\title{
Improving diabetic and hypertensive retinopathy with a medical food containing L-methylfolate: a preliminary report
}

Jianhua Wang ${ }^{1 *}$, Craig Brown², Ce Shi ${ }^{1,3}$, Justin Townsend ${ }^{1}$, Giovana Rosa Gameiro ${ }^{1}$, Peng Wang ${ }^{1,4}$ and Hong Jiang ${ }^{1}$

\begin{abstract}
Background: Homocysteine and vitamin D may play a role in the development of diabetic and hypertensive retinopathy in patients with diabetes mellitus (DM) and hypertension. Supplementing food with L-methylfolate and vitamin $\mathrm{D}$ theoretically may improve diabetic and hypertensive retinopathy, however, the outcome of these nutritional approaches has not been fully examined. A retrospective case review was done of cases of retinopathy reversal in patients on Ocufolin ${ }^{T M}$ and a similar nonprescription multivitamin, Eyefolate ${ }^{T M}$. In this study, they were administered L-methylfolate (2.7 mg and $3.0 \mathrm{mg}$, respectively) and vitamin D3 (4500 IU each). These dosages are significantly above the RDA but well below levels associated with toxicity.

Case presentation: Seven patients had nonproliferative diabetic retinopathy (NPDR) and some of them had hypertension. One patient had only hypertensive retinopathy. All patients were instructed to take Ocufolin ${ }^{\mathrm{TM}}$ medical food as a food supplement. Baseline genetic testing for MTHFR polymorphisms was conducted. Fundus photography was used to document the fundus condition of the enrolled eyes in 8 NPDR patients at the initial and follow-up visits. Microaneurysms (MA) and exudates were observed to be improved in some trial patients. All subjects had one or more MTHFR polymorphisms. All had diabetic retinopathy, hypertensive retinopathy, or both. MAs were resolved, and exudates were decreased in $8 / 8$ cases after taking the medical food. Retinal edema was found in 2/8 cases and improved or resolved in both cases after taking the medical food or the supplement. The best corrected visual activity was stable or improved in $8 / 8$ cases.
\end{abstract}

Conclusion: We report a series of diabetic and hypertensive retinopathy cases with MTHFR polymorphisms and the improvement of retinal microvasculature (mainly MAs) in serial fundus photography after taking a medical food or supplement containing L-methylfolate and vitamin D. It appears that the use of nutritional supplements and medical foods containing L-methylfolate and vitamin D may be effective in facilitating the improvement of diabetic and hypertensive retinopathy.

Keywords: Diabetes, Homocysteine, L-methylfolate, Microaneurysms, MTHFR C677T, Retinopathy, Vitamin D

\section{Background}

As one of the major complications of diabetes mellitus (DM), diabetic retinopathy (DR) is the leading cause of new cases of blindness among working-age adults $[1,2]$. Diabetes and diabetic retinopathy are rapidly becoming more serious and are increasingly prevalent healthcare

\footnotetext{
* Correspondence: jwang3@med.miami.edu

${ }^{1}$ Bascom Palmer Eye Institute, University of Miami, Miller School of Medicine, 1638 NW 10th Avenue, McKnight Building - Room 202A, Miami, FL 33136, USA

Full list of author information is available at the end of the article
}

issues. Hypertension is a major risk factor for DR. Worldwide, there are more than 94 million people with DR [3]. Studies suggest that in the US, there are over 7.6 million diabetics with DR and another 6.6 million prediabetics with DR. Combined, there are 14,000,000 people with DR which, if untreated, can progress to visual disability $[4,5]$.

DR is commonly described as a microvascular disease whose drivers include increased renin-angiotensin systemic dysfunction, increased vascular inflammatory

(c) The Author(s). 2019 Open Access This article is distributed under the terms of the Creative Commons Attribution 4.0 International License (http://creativecommons.org/licenses/by/4.0/), which permits unrestricted use, distribution, and 
response, deregulation of growth factors, and increased vascular permeability [6]. The current standard of care treatments is the injection of anti-VEGF drugs and the use of laser photocoagulation to slow vision loss and occasionally improve vision. However, these treatments are costly, invasive, stressful, and time-consuming for both doctors and patients. Both are often necessary for more advanced DR, which already pose a threat to vision but are generally avoided in the earlier stages of the disease. Hence, beyond good control of blood sugar and blood pressure, less invasive complementary treatments are needed to slow the progression of early DR. Ideally, such complementary treatments would not interfere with the current standard of care treatments. Previous studies found increased homocysteine associated with diabetic retinopathy $[7,8]$. The homocysteine affects vascular endothelial growth factor in the retina $[9,10]$, which is also associated with the regulation of angiogenesis [11]. Reducing homocysteine is one such approach that addresses another driver of DR, without impairing antiVEGF and laser therapies.

The methylenetetrahydrofolate reductase gene (MTHFR) encodes for methylenetetrahydrofolate reductase, an enzyme involved in the methylation of B12 and homocysteine [12-15]. The MTHFR polymorphisms impair enzymatic activity, resulting in decreased serum L-methylfolate, serum methylcobalamin, and elevated serum homocysteine levels. These have been shown to cause hypertension [12-14], small vessel disease, and DR [16]. The MTHFR polymorphisms thus contribute to diabetic and hypertensive retinal vasculopathy [12-14, 17-20].

Vitamin D is a key regulator of several important metabolic functions [21, 22]. Vitamin D insufficiency is associated with increased CRP, arterial stiffness, and endothelial dysfunction [22]. Vitamin D deficiency increases levels of parathyroid hormone (PTH), which increases insulin resistance and is associated with an increased incidence of diabetes [23]. Finally, vitamin D deficiency in type 2 diabetes patients increases the risk of DR [24]. The deficiency of vitamin D may play an important role in the progression and severity of DR [2527].

Treating diabetic and hypertensive retinopathy with vitamin D and L-methylfolate may be helpful; however, the efficacy of these treatments has not been fully studied. Food supplementation is safe, simple, and inexpensive. A previous study reported that folic acid therapy reduces the risk of stroke [28]. Folic acid supplementation was also found to be associated with reduced risk of retinal microangiopathy in adults with hypertension complicated with DM [17]. Another study reported that the medical food Ocufolin $^{\text {nx }}$ may have a marked improvement in retinal artery occlusion outcome as late as $24 \mathrm{~h}$ post occlusion [29]. L-methylfolate (5-MTHF) more readily crosses the blood brain barrier and blood retinal barrier than folic acid and has less toxicity than folic acid, thus making it a more potent choice for retinal therapy than folic acid [30-32]. Here, we present the findings of 8 patients with diabetic and/or hypertensive retinopathy who took food supplements with supratherapeutic levels of L-methylfolate and vitamin D.

\section{Case presentation Methods}

During a prospective study of the effects of medical food, Ocufolin ${ }^{\mathrm{ma}}$ on retinal blood flow in patients with diabetic retinopathy, visible improvements of baseline retinopathy were noted. This prompted a retrospective review of other patients treated with Ocufolin ${ }^{\text {Tm }}$ and a similar product, Eyefolate ${ }^{\text {Tx }}$ for visible improvements of retinopathy.

We reviewed 7 retrospectively identified cases from the Eye Center, Fayetteville, AR and 1 case from Bascom Palmer Eye Institute, University of Miami, Miami, FL. This study was performed from Oct 2013 to Dec 2018. The Washington Regional Institutional Review Board waived review of this retrospective case study of anonymized case data from the Fayetteville site, and the University of Miami Institutional Review Board approved the prospective study conducted at the University of Miami. Written informed consent to be included in this study was obtained from each study subject.

All subjects had been examined by experienced ophthalmologists. Every patient received a full ophthalmic examination including slit-lamp biomicroscopy, intraocular pressure (IOP) measurement, refraction, best corrected visual acuity (BCVA) and fundus indirect ophthalmoscopic examination, and fundus photography. Baseline diabetic retinopathy severity scores were determined by the retinal specialist, according to the International Clinical Diabetic Retinopathy Disease Severity Scale. Genetic testing was performed by MyGenetx Laboratory, LLC (Franklin, TN) or Quest Diagnostics. In addition, other blood tests were performed by Quest Diagnostics, including homocysteine, vitamin D, vitamin B12 and HbA1c. Standard fundus photos were taken using a Zeiss Visucam NM/FA at the Fayetteville Eye Center. A Topcon (50DX, Topcon Medical Systems, Inc., Oakland, NJ) fundus camera and a Zeiss Clarus fundus camera (Model 500, Carl Zeiss Meditec, Inc., Dublin, CA) were used at the Bascom Palmer Eye Institute.

Case 8 was one of the patients recruited in a prospective clinical study using Ocufolin ${ }^{\text {Tu }}$ medical food supplementation at the Bascom Palmer Eye Institute. This patient was imaged using the retinal function imager (RFI), an advanced ophthalmic imaging modality based on a fundus camera. The retinal blood flow velocity was measured. The detailed information and applications of 
RFI were reviewed previously [33]. Before the study, the pupil of this patient was dilated with $1 \%$ tropicamide. A field of view of $4.3 \times 4.3 \mathrm{~mm}^{2}$ (20 degrees) was used. The retinal blood flow velocity was measured in the arterioles and venules.

\section{Results}

Basic information from the 8 cases is presented in Table 1. All subjects were Caucasians and diagnosed with nonproliferative diabetic retinopathy (NPDR) and/ or hypertensive retinopathy (HR). Three were females and five were males.

Among them, 7 subjects took Eyefolate ${ }^{\text {Tm }}$ (3 subjects switched to Ocufolin ${ }^{\text {ts }}$ ) and one subject took only Ocufo$\operatorname{lin}^{\mathrm{Tw}}$. Detailed information of these formulations is listed in Table 2. During the food supplement treatment period, 2 subjects had BCVA improvement and 3 subjects had mild BCVA decline (Table 3 ). The remaining 3 subjects remained at the same BCVA. All subjects showed resolution of intra-retinal hemorrhages, microaneurysms (MA), and or the reduction of exudates on the fundus photograph. Detailed information of each case is presented below.

\section{Case 1}

A 67-year-old woman presented with bilateral NPDR and treated hypertension. BCVA was 20/40-2 OU at the first visit in April 2014. Fundus photos showed multiple MAs, mild dot and blot retinal hemorrhages with some exudates in the right eye (OD) (Fig. 1a). She was instructed to take 3 capsules of Eyefolate ${ }^{\mathrm{Tm}}$ daily with food. In October 2015, the BCVA was 20/50 in OD, and $20 / 30$ in the left eye (OS). Reduced MAs and retinal hemorrhages were observed (Fig. 1b). At that visit, mild
Table 2 Ingredients of two food supplements mentioned in this study (per capsule). Dose: 3 capsules with the breakfast meal

\begin{tabular}{lll}
\hline Ingredient (each capsule contains) & Eyefolate $^{\text {TM }}$ & Ocufolin $^{\text {TM }}$ \\
\hline Metafolin ${ }^{\mathrm{R}}$ L methylfolate & $1000 \mathrm{mcg}$ & $900 \mathrm{mcg}$ \\
Vitamin C & $45 \mathrm{mg}$ & $45 \mathrm{mg}$ \\
Vitamin D & $1500 \mathrm{IU}$ & $1500 \mathrm{IU}$ \\
Vitamin E & $-0-$ & $7.5 \mathrm{IU}$ \\
(natural tocopherols) & $1 \mathrm{mg}$ & $1.5 \mathrm{mg}$ \\
Vitamin B1 & $10 \mathrm{mg}$ & $10 \mathrm{mg}$ \\
Vitamin B2 & $15 \mathrm{mg}$ & $-0-$ \\
Vitamin B3 & $2 \mathrm{mg}$ & $3 \mathrm{mg}$ \\
Vitamin B6 (P-5-P) & $100 \mathrm{mcg}$ & $-0-$ \\
Vitamin B7 (Biotin) & $500 \mathrm{mcg}$ & $500 \mathrm{mcg}$ \\
Vitamin B12 & & \\
(methylcobalamin) & $5 \mathrm{mg}$ & $5 \mathrm{mg}$ \\
Calcium-D-Pantothenate & & \\
(Vitamin B5) & $25 \mathrm{mg}$ & $26.75 \mathrm{mg}$ \\
Zinc Oxide & $20 \mathrm{mcg}$ & $20 \mathrm{mcg}$ \\
L-Selenomethionine & $0.667 \mathrm{mg}$ & $0.667 \mathrm{mg}$ \\
Cupric Oxide & $-0-$ & $180 \mathrm{mg}$ \\
N-Acetyl Cysteine & $180 \mathrm{mg}$ & $-0-$ \\
Alpha Lipoic Acid & $3.35 \mathrm{mg}$ & $3.35 \mathrm{mg}$ \\
Lutein & $250 \mathrm{mcg}$ & $700 \mathrm{mcg}$ \\
Zeaxanthin & $50 \mathrm{mcg}$ & $-0-$ \\
Astaxanthin & & \\
\hline
\end{tabular}

diabetic cystoid macular edema (CME) was found in the OCT image (Fig. 1d). In September 2018, the subject received bilateral intraocular lens (IOL) implantation surgery after which the BCVA improved to 20/30 in OD and $20 / 25$ in OS. The right eye showed fewer

Table 1 Basic information, gene and medical food of the current series of subjects

\begin{tabular}{|c|c|c|c|c|c|c|c|c|}
\hline Subject & $\begin{array}{l}\text { Age } \\
\text { (years) }\end{array}$ & Race & Gender & $\begin{array}{l}\text { Present } \\
\text { DR stage }\end{array}$ & Gene type & Medical Food & $\begin{array}{l}\text { Medical Food } \\
\text { treatment duration } \\
\text { (years) }\end{array}$ & $\begin{array}{l}\text { Other ophthalmic } \\
\text { complications }\end{array}$ \\
\hline 1 & 62 & Caucasian & Female & NPDR OU & MTHFR C677T/A1298C & Eyefolate & 4 & Cataract OU \\
\hline 2 & 82 & Caucasian & Female & NPDR OU & MTHFR C677T/A1298C & Eyefolate & 4 & Dry Macular Degeneration \\
\hline 3 & 84 & Caucasian & Female & NPDR OU & $\begin{array}{l}\text { MTHFR C677TT } \\
\text { Homozygous }\end{array}$ & Eyefolate & 5 & $\begin{array}{l}\text { Low Tension Glaucoma, } \\
\text { Branch retinal vein } \\
\text { occlusion OS }\end{array}$ \\
\hline 4 & 59 & Caucasian & Male & NPDR OU & $\begin{array}{l}\text { MTHFR C677TT } \\
\text { Homozygous }\end{array}$ & $\begin{array}{l}\text { Eyefolate } \\
\text { \& Ocufolin }\end{array}$ & 3 & $\begin{array}{l}\text { Glaucoma suspect, Peripheral } \\
\text { Neuropathy, Cataract }\end{array}$ \\
\hline 5 & 76 & Caucasian & Male & non diabetic & MTHFR C677T/A1298C & Eyefolate & 4 & $\begin{array}{l}\text { Hypertension, small BRVO, } \\
\text { Age-related Macular } \\
\text { degeneration OU, cataract OU }\end{array}$ \\
\hline 6 & 56 & Caucasian & Male & NPDR OU & $\begin{array}{l}\text { MTHFR A1298CC } \\
\text { Homozygous }\end{array}$ & $\begin{array}{l}\text { Eyefolate } \\
\& \text { Ocufolin }\end{array}$ & 3 & $\begin{array}{l}\text { Vitreous Hemorrhage OS, } \\
\text { Vitrectomy OU }\end{array}$ \\
\hline 7 & 64 & Caucasian & Male & NPDR OU & None & Eyefolate & 1 & None \\
\hline 8 & 68 & Caucasian & Male & NPDR OS & None & Ocufolin & 0.5 & $\begin{array}{l}\text { Posterior vitreous } \\
\text { detachment OU }\end{array}$ \\
\hline
\end{tabular}


Table 3 The BCVA and fundus photo findings before and after taking medical food

\begin{tabular}{|c|c|c|c|c|c|c|}
\hline Subject & Medical Food & $\begin{array}{l}\text { Medical food } \\
\text { treatment } \\
\text { duration (years) }\end{array}$ & BCVA (before) & BCVA (after) & $\begin{array}{l}\text { Fundus Photo } \\
\text { findings (before) }\end{array}$ & $\begin{array}{l}\text { Fundus Photo } \\
\text { Findings (after) }\end{array}$ \\
\hline 1 & Eyefolate & 4 & $20 / 40 \mathrm{OU}$ & $20 / 30$ OD, 20/25 OS & $\begin{array}{l}\text { Mild dot and blot } \\
\text { retinal hemorrhages, } \\
\text { exudates, CME }\end{array}$ & $\begin{array}{l}\text { Fewer MAs, fewer } \\
\text { hemorrhages, } \\
\text { less CME }\end{array}$ \\
\hline 2 & Eyeflolate & 4 & HM OD, 20/20 OS & HM OD, 20/25 OS & $\begin{array}{l}\text { Intra-retinal hemorrhages } \\
\text { and } 2 \text { small MAs }\end{array}$ & Only 1 faint MA left \\
\hline 3 & Eyeflolate & 5 & $20 / 150$ OD, 20/25 OS & 20/400 OD, 20/25 OS & $\begin{array}{l}\text { Large MA, Exudates, } \\
\text { mild CME }\end{array}$ & $\begin{array}{l}\text { MA resolved, Exudate } \\
\text { resolved, CME decreased }\end{array}$ \\
\hline 4 & $\begin{array}{l}\text { Eyefolate } \\
\& \text { Ocufolin }\end{array}$ & 3 & $20 / 20$ OU & N/A & $\begin{array}{l}\text { Multiple MAs and } \\
\text { retinal hemorrhages }\end{array}$ & $\begin{array}{l}\text { MAs and retinal } \\
\text { hemorrhages resolved }\end{array}$ \\
\hline 5 & Eyefolate & 4 & $20 / 20$ OU & $20 / 40$ OD, 20/25 OS & Multiple MAs and exudates & $\begin{array}{l}\text { Multiple MAs and } \\
\text { exudates resolved on } \\
\text { Eyefolate then recurred } \\
\text { after he discontinued } \\
\text { them. }\end{array}$ \\
\hline 6 & $\begin{array}{l}\text { Eyefolate } \\
\& \text { Ocufolin }\end{array}$ & 3 & $20 / 30$ OD, 20/400 OS & $20 / 25+1$ OD, 20/200 OS & $\begin{array}{l}\text { Some MAs, exudates, } \\
\text { silver wiring }\end{array}$ & $\begin{array}{l}\text { MAs and exudates } \\
\text { resolved, persistent } \\
\text { silver wiring }\end{array}$ \\
\hline 7 & Eyefolate & 1 & & & Intra-retinal hemorrhage & $\begin{array}{l}\text { Intra-retinal hemorrhage } \\
\text { resolved }\end{array}$ \\
\hline 8 & Ocufolin & 0.5 & $20 / 20 \mathrm{OU}$ & $20 / 20$ OU & MA & MA resolved \\
\hline
\end{tabular}

BCVA best corrected visual acuity, HM hand motion, MA microaneurysms, CME cystic macular edema

hemorrhages and MA (Fig. 1c) and less CME on OCT examination (Fig. 1e).

\section{Case 2}

An 82-year-old woman presented with diet-controlled type 2 diabetes and medication controlled hypertension. In June 2014, the BCVA in OD was hand movement
(HM) due to an old macular scar and the BCVA in OS was 20/20. Intra-retinal hemorrhages and 2 small MAs were found in the fundus photo OS (Fig. 2a). She began 3 capsules of Eyefolate ${ }^{\mathrm{Tx}}$ daily with breakfast. In October 2014, her BCVA remained HM in OD and 20/25 OS, but the hemorrhages resolved and only 1 faint MA was seen in the fundus photography in OS (Fig. 2b).
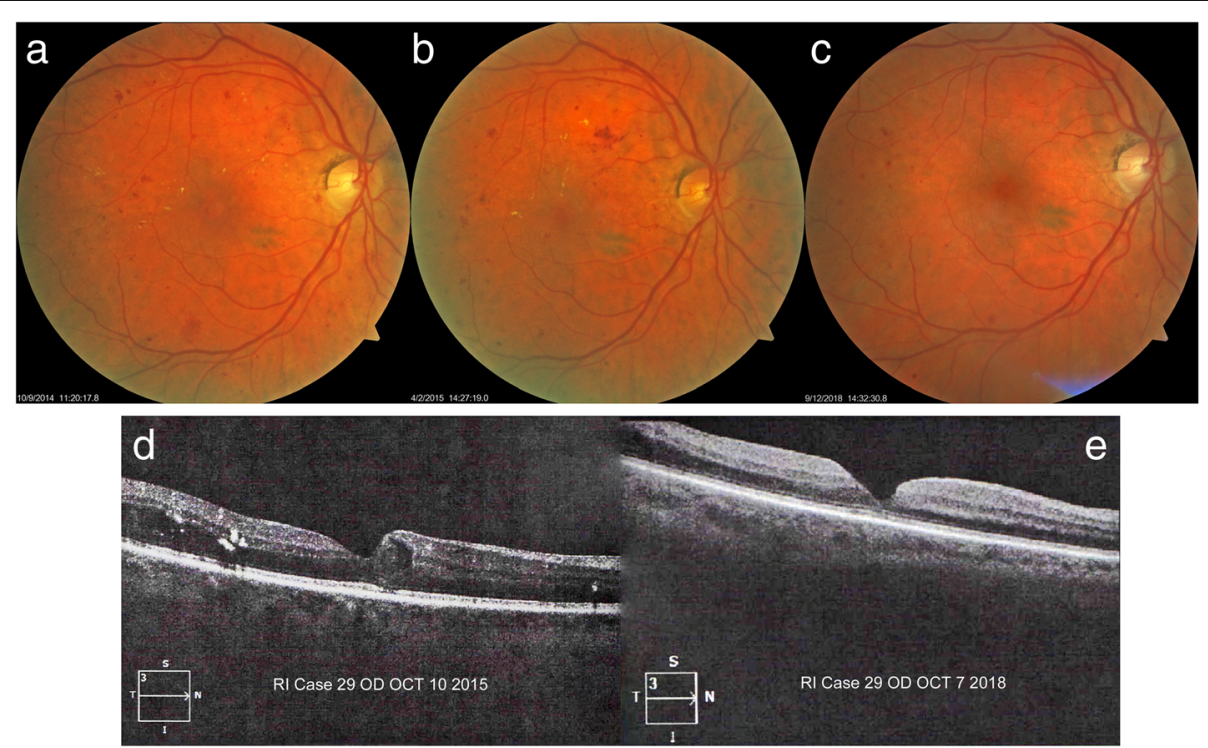

Fig. 1 Follow-up of first case fundus photos and OCT images. The fundus photograph fewer hemorrhages and MAs after taking Eyefolate ${ }^{\text {TM }}(\mathbf{a}, \mathbf{b}$, c). The diabetic cystic macular edema resolved at a later visit (e) on the OCT B-scan using Zeiss Cirrus HD-OCT (Model 5000) compared to the previous visit (d). OCT: optical coherence tomography; MA: microaneurysms 


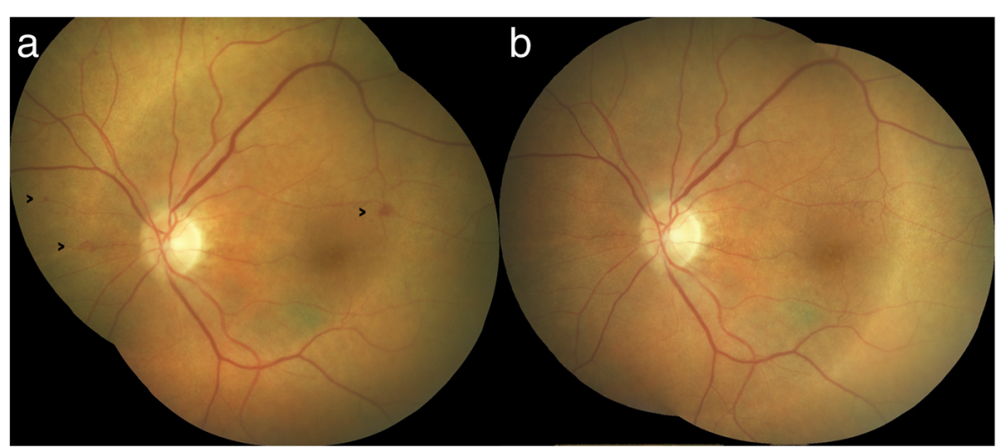

Fig. 2 Follow-up of the second case fundus photos. Intra-retinal hemorrhages and 3 small MAs (black arrows) were seen in the fundus photo in OS eye (a) at the first visit. At the second visit, only 1 faint MA remained, and the hemorrhages were resolved (b) after taking Eyefolate ${ }^{\mathrm{TM}}$ for four months. MA: microaneurysms

\section{Case 3}

An 84-year-old woman presented with a seven-year history of type 2 diabetes and medically controlled hypertension. She had a history of amblyopia OD and a resolved branch retinal vein occlusion (BRVO) in the left eye. In October 2013, the BCVA was 20/150 OD and 20/25 OS. A large MA in the superior temporal region with exudates is seen in the fundus photo OS. She was instructed to take 3 capsules of Eyefolate ${ }^{\mathrm{Tm}}$ daily. In August 2014, the BCVA was 20/200 OD and BCVA OS was improved to 20/20. Decreased exudation was found in OS fundus photo (Fig. 3a). In December 2014, the BCVA was 20/200 OD and 20/25 OS. The large exudates had almost completely resolved OS (Fig. 3b). In January 2016, the BCVA was 20/400 OD and 20/25 OS.
The MA was resolved in the OS fundus photo (Fig. 3c) in 2016.

\section{Case 4}

The fourth case was a 59-year-old man with an 11-year history of type 2 diabetes who had required insulin for the past 8 years. On his first visit in October 2014, the BCVA was $20 / 20$ OU. Multiple small intra-retinal hemorrhages and MAs with exudates superotemporally were found OS as seen in the fundus image (Fig. 4a). He began 3 capsules of Eyefolate $^{\mathrm{Tm}}$ daily. In October 2015, the number of retinal hemorrhages and MAs declined OS (Fig. 4b), then he switched from Eyefolate $^{\mathrm{TM}}$ to Ocufolin ${ }^{\mathrm{TM}}$. In April 2016, the number of hemorrhages and MAs continued to decline, and the exudates resolved OS (Fig. 4c).
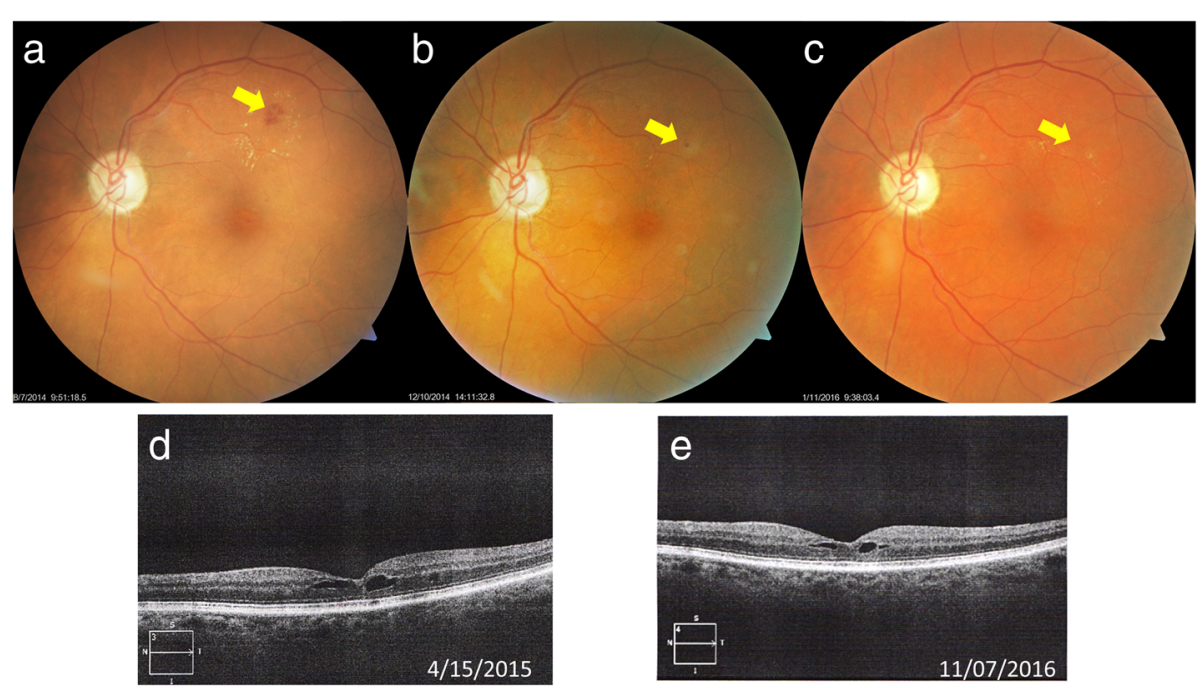

Fig. 3 Follow-up of third case fundus photos. Some exudate leakage was found at the August 2014 visit (a). After taking Eyefolate ${ }^{T M}$, the large MA (yellow arrow) was reduced and the exudate was smaller at the Dec 2014 visit (b). The MA and exudates (yellow arrow) were resolved by the January 2016 visit (c). In addition, at the November 16 visit (e), the diabetic cystic macular edema was reduced from the 2015 visit (d) and later visit 


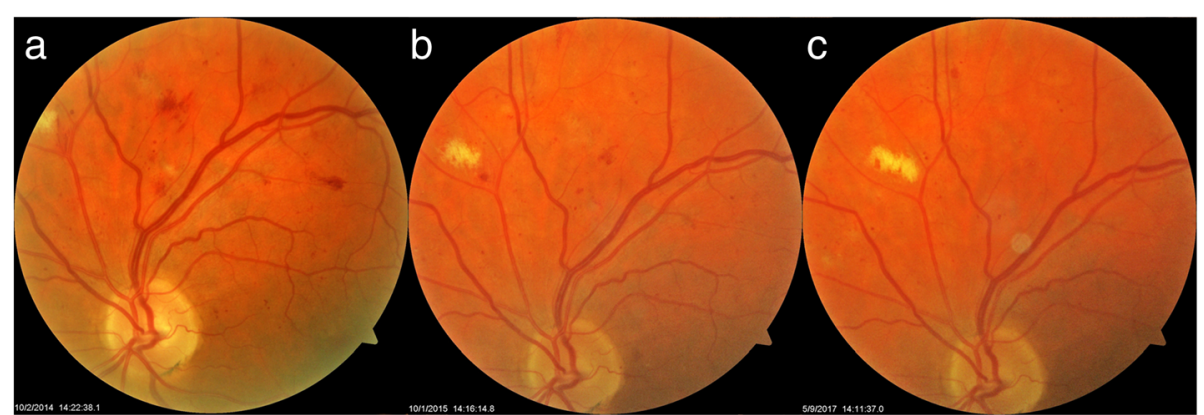

Fig. 4 Follow-up of the fourth case fundus photos. The number of retinal hemorrhages and MAs on the fundus photo declined and exudates were resolved after taking the supplements (a-c). MA: microaneurysms

\section{Case 5}

A 76-year-old nondiabetic man was examined with a 10 year history of medication controlled hypertension and dry age-related macular degeneration (AMD) (drusen) OU. In June 2014, multiple small MAs with exudates and one cotton wool spot was found OD as seen in the fundus photo (Fig. 5a) inferotemporal to small drusen. The retinopathy was likely initiated by a small BRVO, with hypertension as a continuing co-factor, the BCVA was 20/20 OU. He began to take 3 capsules of Eyefolate ${ }^{\text {тм }}$ daily. In December 2014, resolution of the cotton wool spot, exudates, and MAs was found OD (Fig. 5b). In May 2018, smaller MAs and exudates reappeared in the original locations after he had self-discontinued the Eyefolate $^{\mathrm{Tm}}$ (Fig. 5c).

\section{Case 6}

The sixth case was a 56-year-old man with a 15 -year history of NPDR OU. He had a remote history of panretinal photocoagulation and Avastin injections for the severe proliferative disease. In June 2015, his BCVA OD was 20/30, his BCVA OS was HM. He had bilateral intra-retinal hemorrhages and MAs with old retinal scarring and silver wiring of the vessels. He began taking 3 capsules of Eyefolate $^{\mathrm{Tm}}$. In July 2015, his BCVA remained at 20/30 OD but improved to 20/400 OS. He switched from Eyefolate ${ }^{\mathrm{TM}}$ to Ocufolin ${ }^{\mathrm{Tm}}$. In May 2016, his BCVA of this patient remained at $20 / 25+1$ OD and improved to 20/200 OS. Figures 6d-f OD shows resolution of intraretinal hemorrhages and MAs between 12/2015 and 5/ 2018. Figures 6a-c OS show resolution of intra-retinal hemorrhages and exudates. MAs improved then remained stable over more than 3 years of follow up from 12/2015 through February 2019.

\section{Case 7}

The seventh case was a 64-year-old man with a 10 year history of medication controlled hypertension and newly diagnosed type 2 diabetes. In August 2018, a diabetic intra-retinal hemorrhage was found OS (Fig. 7a) and he then began to take Eyefolate ${ }^{\mathrm{TM}}$. By December 2018, the intra-retinal hemorrhage was resolved (Fig. 7b).

\section{Case 8}

The eighth case was a 68-year-old man with NPDR OS. Initially, he was diagnosed with mild NPDR OS (October 2017). The BCVA was 20/20 OU. A MA was apparent in the superonasal quadrant OS in 2017 (Fig. 8). He participated in a clinical trial of Ocufolin ${ }^{\mathrm{TM}}$ at the Bascom Palmer Eye Institute, University of Miami and was

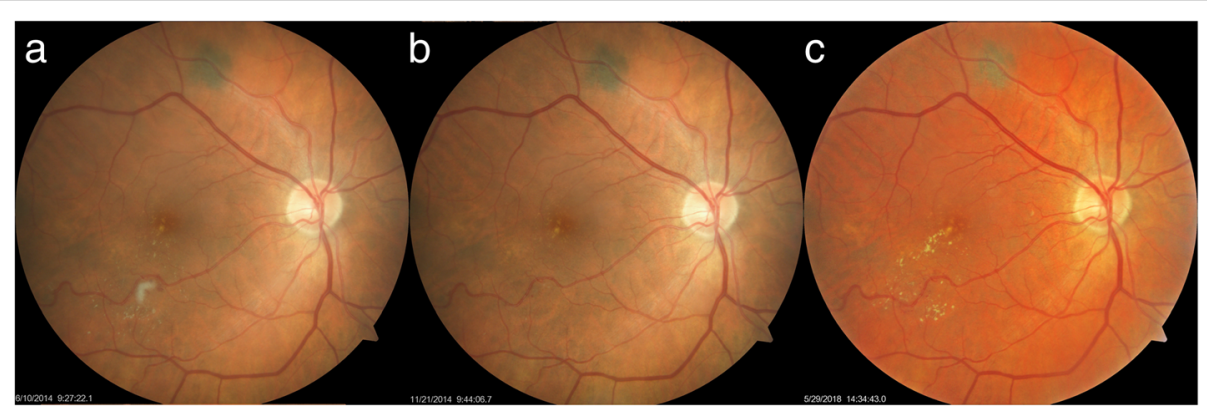

Fig. 5 Follow-up of fifth case fundus photos. Baseline findings of drusen, exudates, a cotton wool spot and microaneurysms (a). MAs were smaller and the exudates and cotton wool spot resolved after taking Eyefolate ${ }^{\mathrm{TM}}$ for 5 months (b). MAs and exudates returned 3 $1 / 2$ years after quitting Eyefolate ${ }^{\mathrm{TM}}(\mathbf{c})$. The foveal drusen did not change. MA: microaneurysms 

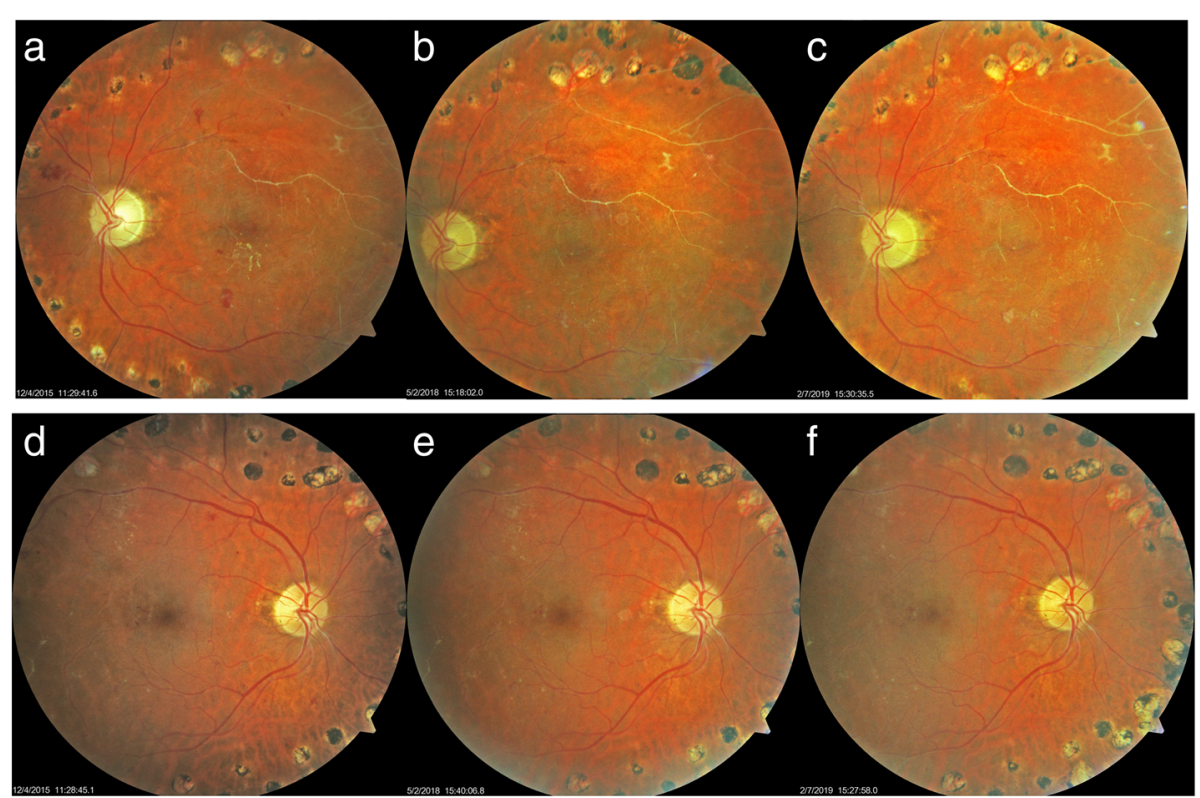

Fig. 6 Follow-up of sixth case fundus photos. After taking Eyefolate ${ }^{\mathrm{TM}}$ then Ocufolin ${ }^{\mathrm{TM}}$, MAs, and exudates resolved. He remains free of MAs and exudates in 2/2019 (c). OS show resolution of intra-retinal hemorrhages, exudates, and MAs improved and remained stable over more than 3 years of follow up from 12/2015 through February 2019 (a-c). OD show resolution of intra-retinal hemorrhages and MAs between 12/2015 and 5/ 2018 (d-f). MA: microaneurysms

instructed to take Ocufolin ${ }^{\text {Tx }}$ on December 19, 2017. During the April 2018 office visit, the BCVA remained 20/20 OU and the macular edema had resolved (Fig. 8). A dilated fundus examination indicated no visible retinopathy. In January 2019, a dilated fundus documented absence of macular edema and no evidence of background diabetic retinopathy (Fig. 8). Detailed inspection of the fundus photos shows two small MAs in the superior nasal periphery of the OS eyes in the fundus photo taken in October 2017 and resolved in the photo taken in January 2019. The retinal blood flow was increased at the sixmonth study visit (June 11, 2018, Fig. 9).

\section{Discussion and conclusions}

DM and hypertension cause microvascular abnormalities, including DR and hypertensive retinopathy (HR) [14, 34-37]. Microvascular abnormalities, especially retinal arterial narrowing and retinal hemorrhages, have been used to monitor the impact on the microvasculature in the body as a whole, in the central nervous system, and small vessel white matter disease [38, 39]. In addition, retinopathy poses a threat to vision and may cause blindness. Small vessel abnormalities and formation and turnover rates of MAs in the retina have been regarded as reliable predictors of the onset and progression of DR [28]. The newer MAs in successive fundus

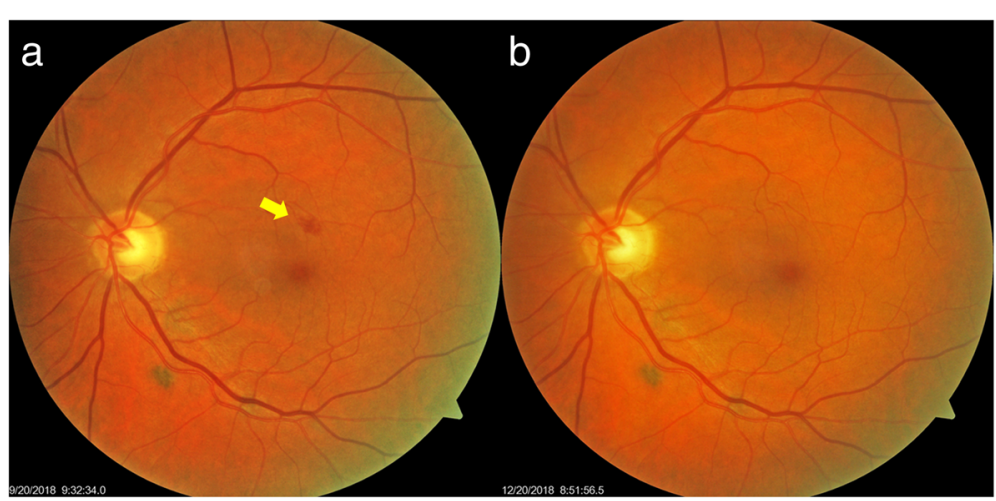

Fig. 7 Follow-up of seventh case fundus photos. Between September 2018 (a) and December 2018 (b), the intra-retinal hemorrhage (yellow arrow) resolved after taking Eyefolate ${ }^{\mathrm{TM}}$ 

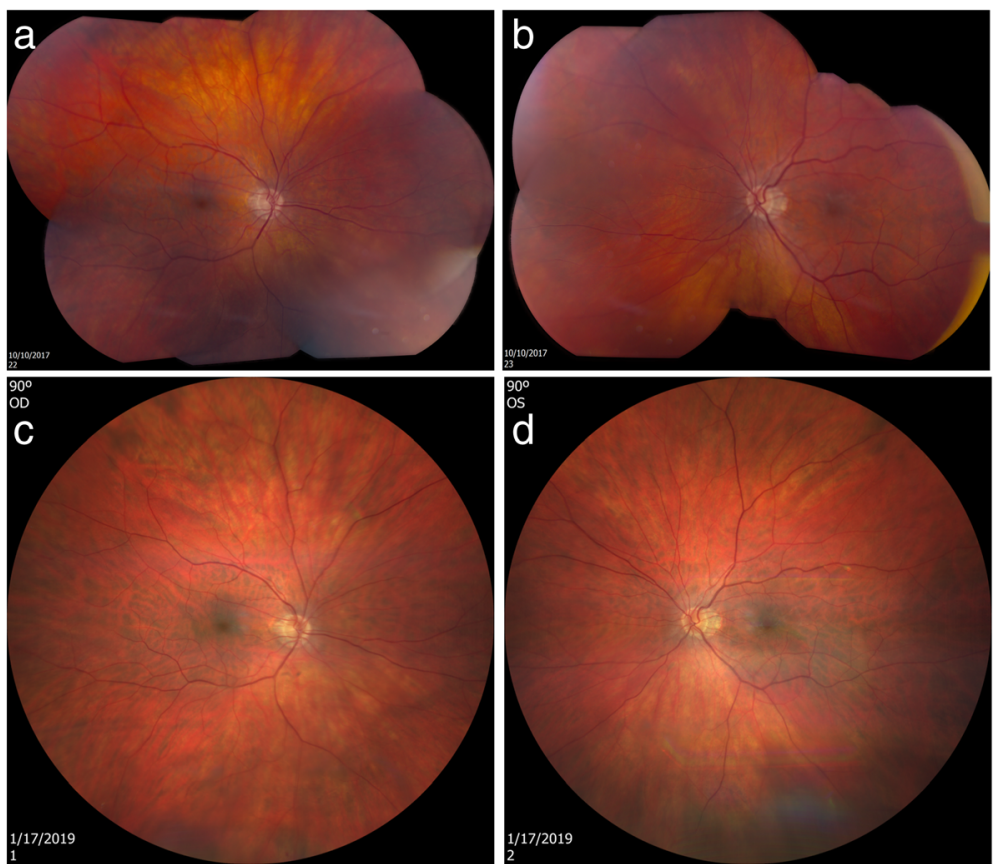

Fig. 8 Follow-up of eighth case fundus photos. The top images were taken using Topcon DX fundus camera on October 10, 2017, before the patient took Ocufolin ${ }^{\mathrm{TM}}(\mathbf{a}, \mathbf{b})$. Close inspection of fundus photos showed two MAs in the periphery of the superonasal quadrant OS. The bottom photos were taken using Zeiss Clarus 500 on January 17, 2019, after the patient participated in a clinical trial of Ocufolin ${ }^{\text {TM }}$ for 6 months (c, d). The MAs in the superior nasal periphery of the OS eye resolved in the photo taken in January 2019

photographs, the higher probability of progression in vision-threatening DR [40].

Our study presents a case series of patients with NPDR and HR and their findings after taking a medical food containing L-methylfolate and vitamin D. The primary findings were the resolution of retinal hemorrhages and MAs, as well as the reduction of exudates and macular edema. This suggests that a supplement or medical food containing therapeutic doses of L-

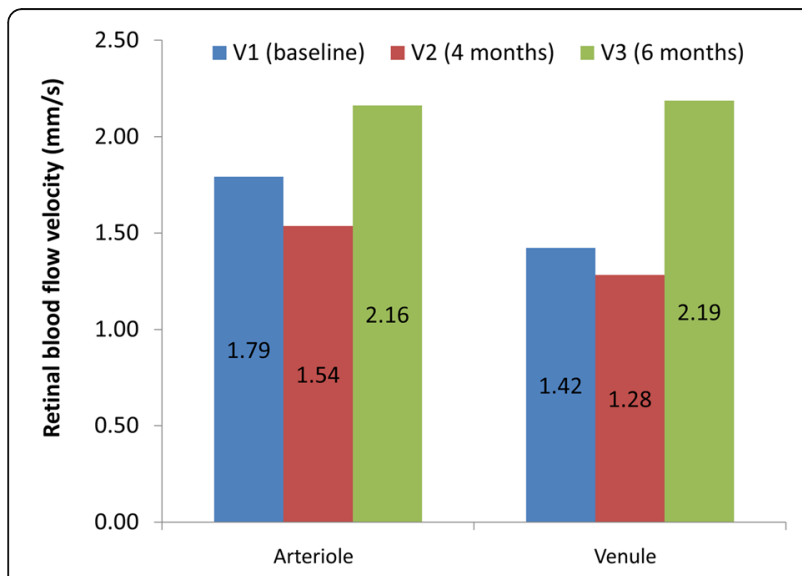

Fig. 9 Retinal blood flow velocity of the eighth case. Retinal blood flow velocity was measured during study period of 6 months when the patient took Ocufolin ${ }^{\mathrm{TM}}$ methylfolate and vitamin D may be a safe and noninvasive addition to our treatments of NPDR and HR.

Both Eyefolate $^{\mathrm{Tm}}$ and Ocufolin ${ }^{\mathrm{Tw}}$ contain L-methylfolate, which targets the ischemic consequences of reduced function polymorphisms of the MTHFR gene in patients with DM. Wicken et al. reported that the C667T was present in $40 \%$ of the Caucasian American population, $50 \%$ of Europeans and a lower percentage in AfricanAmericans and Asian-Americans [41]. MTHFR C677T and $\mathrm{A} 1298 \mathrm{C}$ polymorphisms lead to a reduction in the methylation of tetrahydrofolate, which results in decreased available L-methylfolate, methylcobalamin (methyl B12), and the elevation of homocysteine. These further lead to elevated blood pressure damaging the small vessels [42].

In a recent study of 24 patients with DM, plasma homocysteine concentration was significantly decreased after 3 months of taking Ocufolin ${ }^{\mathrm{Tm}}$ [43]. In that study, retinal blood flow measured using Doppler OCT did not reach a significant level. However, only 1 capsule of Ocufolin $^{\text {Tu }}$ was taken during that study period, which may have been too low a dose to affect retinal blood flow [43]. In contrast, all cases reported here took 3 capsules daily. Case 8 in our study had increased retinal blood flow velocity, which was directly measured using RFI. We hypothesize that decreased homocysteine resulted in improved retinal blood flow due to the mitigation of homocysteine-induced narrowing of retinal 
artery caliber [44]. Since Eyefolate ${ }^{\mathrm{Tx}}$ and Ocufolin ${ }^{\mathrm{Tx}}$ lower homocysteine [43], their use seems to lead to an improvement in retinal blood flow, resulting in the improvement of retinopathy. The findings of our series of patients with retinopathy support the speculation, although further clinical studies are necessary.

Several vascular diseases such as ischemic cerebral stroke, small vessel disease, and retinal vein occlusion have been found to associate with MTHFR polymorphisms [28, 37, 45]. Also, MTHFR polymorphisms are commonly recognized risk factors for retinal vascular disease, including DR progression [34]. Case 5 seems to demonstrate improvement in retinal vein occlusion after the use of the medical food. Huo et al. reported that folic acid therapy could reduce the risk of the first stroke, suggesting that a similar approach may slow the progression of vascular disease [8]. Studies show that Lmethylfolate is a better choice than folic acid with reduced toxicity and better penetration of the central nervous system and retina [30-32].

The improvement of DR of our patients that may also in part be attributed to the pharmacological doses of vitamin $\mathrm{D}$ in the present study. Vitamin D plays a role in anti-inflammatory and immunosuppressive activities and its potential inhibitory effect on angio-neogenesis has been hypothesized [24, 46, 47]. Hypovitaminosis of vitamin D increases the risk of DM [46-48]. Among DM patients, vitamin D deficiency is found to associate with a higher risk of DR [24, 46-48]. The potential relationship between vitamin D status and the DR severity is still controversial $[49,50]$. Brown reported a case of branch retinal artery occlusion treated more than $24 \mathrm{~h}$ post occlusion with Ocufolin ${ }^{\text {Tw }}$ with a remarkably improved outcome [29]. Our findings support these earlier reports that the microvascular abnormalities (i.e., hemorrhages, MAs, exudates, and macular edema) were reduced after taking the products containing Lmethylfolate and vitamin D.

BCVA is an important component of the visual function. Stability or improved BCVA is the desired outcome treatment of DR. However, DR is often associated with other vision damaging diseases. Case 2 showed a decreased BCVA, which may be due to concurrent AMD. In other cases, amblyopia, cataract, and preexisting vascular disease affected the visual outcomes. Encouragingly, the BCVA in the majority of cases remained stable during the study period. Further study with larger sample sizes and more strict inclusion criteria may help identify the effect of these nutrients on BCVA.

As the first report of a retrospective series of cases that shows a beneficial effect of nutritional supplementation of vitamin D and L-methylfolate on DR and HR, our study also has several limitations. It is not prospective. The lack of a quantitative tool impairs objective observation of the progression of DR and quantification of the dose effect. Further prospective studies with more advanced image modalities such as OCT angiography may provide a better understanding of the benefits to the retinal microvasculature. Second, all patients identified with this positive response were adult Caucasians. Prospective studies with larger sample sizes and community-based studies can stratify patients with racial diversity and their outcome. Third, as mentioned above, the other ophthalmic conditions of these subjects may affect the observations, due to the limited case series. Further prospective large-scale and double-blind studies are needed. Fourth, although the retinal blood flow was increased in case 8 , results from a larger sample size are needed to validate the findings. Our ongoing prospective retinal blood flow trial with Ocufolin ${ }^{\mathrm{Tw}}$ intervention will shed light on the mechanism of these unusual and encouraging case reports, as reported in the present study.

In conclusion, we report a series of DR and HR cases with MTHFR polymorphisms and improvement of retinal microvasculature (mainly hemorrhages, MAs, and exudates) in fundus photographs. It appeared that the use of a carefully formulated medical food which includes L-methylfolate and vitamin D may be effective in facilitating the improvement of DR. Future clinical trials are also needed to show optimal dosing for such medical foods and supplements.

\section{Acknowledgments}

None.

Authors' contributions

JW, CB, CS, JT, GRG, PW and HJ collected and analyzed the data. JW and CB interpreted the data. CS, PW, CB, HJ and JW were the major contributors for writing the manuscript. All authors read and approved the final manuscript.

\section{Funding}

Grant/financial support: Supported by NIH Center Grant P30 EY014801, and a grant from Research to Prevent Blindness (RPB).

Availability of data and materials

The datasets used and analyzed for the present study are available from the corresponding author.

\section{Ethics approval and consent to participate}

All research methods are by the tenets of the Declaration of Helsinki and approved by the ethics committee board of the University of Miami. All subjects at the University of Miami were recruited voluntarily and were informed about the purposes, methods, and the potential risks of the study. All cases from the clinical practice were obtained by retrospective chart review. Anonymized data was obtained from the medical records. A signed consent form was obtained from each person.

\section{Consent for publication}

All study subjects gave informant consent and signed the informed consent form.

\section{Competing interests}

Dr. Brown holds an ownership interest in Global Healthcare Focus, a small research and development company concerned with developing nutritional products to improve health. Other authors have no competing interests. 


\section{Author details}

'Bascom Palmer Eye Institute, University of Miami, Miller School of Medicine, 1638 NW 10th Avenue, McKnight Building - Room 202A, Miami, FL 33136, USA. ${ }^{2}$ Department of Ophthalmology, College of Medicine, University of Arkansas for Medical Sciences, Fayetteville, AR, USA. ${ }^{3}$ School of Ophthalmology and Optometry, Wenzhou Medical University, Wenzhou, Zhejiang, China. ${ }^{4}$ Department of Ophthalmology, Shanghai General Hospital, Shanghai Jiaotong University School of Medicine, Shanghai, China.

\section{Received: 15 March 2019 Accepted: 1 July 2019}

\section{Published online: 22 July 2019}

\section{References}

1. Grauslund J, Green A, Sjølie AK. Blindness in a 25-year follow-up of a population-based cohort of Danish type 1 diabetic patients. Ophthalmology. 2009;116(11):2170-4.

2. Klein BE. Overview of epidemiologic studies of diabetic retinopathy. Ophthalmic Epidemiol. 2007;14(4):179-83.

3. Yau JW, Rogers SL, Kawasaki R, Lamoureux EL, Kowalski JW, Bek T, et al. Global prevalence and major risk factors of diabetic retinopathy. Diabetes Care. 2012;35(3):556-64.

4 https://nei.nih.gov/eyedata/diabetic. Accessed 18 June 2019

5. http://www.cdc.gov/media/releases/2017/p0718-diabetes-report.html. Accessed 18 June 2019.

6. Ola MS, Nawaz MI, Siddiquei MM, Al-Amro S, Abu El-Asrar AM. Recent advances in understanding the biochemical and molecular mechanism of diabetic retinopathy. J Diabetes Complications. 2012;26(1):56-64.

7. Goldstein M, Leibovitch I, Yeffimov I, Gavendo S, Sela BA, Loewenstein A. Hyperhomocysteinemia in patients with diabetes mellitus with and without diabetic retinopathy. Eye (Lond). 2004;18(5):460-5.

8. Xu C, Wu Y, Liu G, Liu X, Wang F, Yu J. Relationship between homocysteine level and diabetic retinopathy: a systematic review and meta-analysis. Diagn Pathol. 2014:9:167.

9. Atta HM, El-Rehani MA, Raheim SA, Galal AM. Lowering homocysteine decreases levels and expression of VEGF(165) and endostatin. J Surg Res. 2008;146(2):202-10.

10. Roybal CN, Yang S, Sun CW, Hurtado D, Vander Jagt DL, Townes TM, et al. Homocysteine increases the expression of vascular endothelial growth factor by a mechanism involving endoplasmic reticulum stress and transcription factor ATF4. J Biol Chem. 2004;279(15):14844-52.

11. Noma H, Funatsu H, Yamashita H, Kitano S, Mishima HK, Hori S. Regulation of angiogenesis in diabetic retinopathy: possible balance between vascular endothelial growth factor and endostatin. Arch Ophthalmol. 2002:120(8):1075-80.

12. Luo S, Wang F, Shi C, Wu Z. A meta-analysis of association between methylenetetrahydrofolate reductase gene (MTHFR) 677C/T polymorphism and diabetic retinopathy. Int J Environ Res Public Health. 2016;13(8):806.

13. McNulty H, Strain JJ, Hughes CF, Ward M. Riboflavin, MTHFR genotype and blood pressure: A personalized approach to prevention and treatment of hypertension. Mol Asp Med. 2017;53:2-9.

14. Yang B, Fan S, Zhi X, Li Y, Liu Y, Wang D, et al. Associations of MTHFR gene polymorphisms with hypertension and hypertension in pregnancy: a metaanalysis from 114 studies with 15411 cases and 21970 controls. PLoS One. 2014;9(2):e87497.

15. Botto LD, Yang Q. 5,10-methylenetetrahydrofolate reductase gene variants and congenital anomalies: a HuGE review. Am J Epidemiol. 2000;151(9):862-77.

16. Qi Z, Hoffman G, Kurtycz D, Yu J. Prevalence of the C677T substitution of the methylenetetrahydrofolate reductase (MTHFR) gene in Wisconsin. Genet Med. 2003;5(6):458-9.

17. Meng Y, Li J, Chen $X$, She H, Zhao L, Peng Y, et al. Association between folic acid supplementation and retinal atherosclerosis in Chinese adults with hypertension complicated by diabetes mellitus. Front Pharmacol. 2018;9:1159.

18. Brazionis L, Rowley K Sr, Itsiopoulos C, Harper CA, O'Dea K. Homocysteine and diabetic retinopathy. Diabetes Care. 2008;31(1):50-6.

19. Maeda M, Yamamoto I, Fukuda M, Nishida M, Fujitsu J, Nonen S, et al. MTHFR gene polymorphism as a risk factor for diabetic retinopathy in type 2 diabetic patients without serum creatinine elevation. Diabetes Care. 2003; 26(2):547-8

20. Maeda M, Yamamoto I, Fukuda M, Motomura T, Nishida M, Nonen S, et al. MTHFR gene polymorphism is susceptible to diabetic retinopathy but not to diabetic nephropathy in Japanese type 2 diabetic patients. J Diabetes Complicat. 2008:2(2):119-25.

21. Yu Y, Tian L, Xiao Y, Huang G, Zhang M. Effect of vitamin D supplementation on some inflammatory biomarkers in type 2 diabetes mellitus subjects: a systematic review and meta-analysis of randomized controlled trials. Ann Nutr Metab. 2018;73(1):62-73.

22. Al Mheid I, Patel R, Murrow J, Morris A, Rahman A, Fike L, et al. Vitamin D status is associated with arterial stiffness and vascular dysfunction in healthy humans. J Am Coll Cardiol. 2011;58(2):186-92.

23. Grammatiki M, Karras S, Kotsa $\mathrm{K}$. The role of vitamin $\mathrm{D}$ in the pathogenesis and treatment of diabetes mellitus: a narrative review. Hormones (Athens). 2019;18(1):37-48.

24. Luo BA, Gao F, Qin LL. The association between vitamin D deficiency and diabetic retinopathy in type 2 diabetes: a meta-analysis of observational studies. Nutrients. 2017:9(3):307.

25. Reddy GB, Sivaprasad M, Shalini T, Satyanarayana A, Seshacharyulu M, Balakrishna $\mathrm{N}$, et al. Plasma vitamin D status in patients with type 2 diabetes with and without retinopathy. Nutrition. 2015;31(7-8):959-63.

26. Ashinne B, Rajalakshmi R, Anjana RM, Narayan KMV, Jayashri R, Mohan V, et al. Association of serum vitamin D levels and diabetic retinopathy in Asian Indians with type 2 diabetes. Diabetes Res Clin Pract. 2018;139:308-13.

27. Long M, Wang C, Liu D. Glycated hemoglobin A $1 C$ and vitamin D and their association with diabetic retinopathy severity. Nutr Diabetes. 2017:7(6):e281.

28. Huo Y, Li J, Qin X, Huang Y, Wang X, Gottesman RF, et al. Efficacy of folic acid therapy in primary prevention of stroke among adults with hypertension in China: the CSPPT randomized clinical trial. JAMA. 2015; 313(13):1325-35.

29. Brown CJ. Preservation of retinal structure and function after cilioretinal artery occlusion: a case report. Int Med Case Rep J. 2016;9:29-34.

30. Huang W, Prasad PD, Kekuda R, Leibach FH, Ganapathy V. Characterization of N5-methyltetrahydrofolate uptake in cultured human retinal pigment epithelial cells. Invest Ophthalmol Vis Sci. 1997;38(8):1578-87.

31. Knowles L, Morris AA, Walter JH. Treatment with mefolinate (5Methyltetrahydrofolate), but not folic acid or folinic acid, leads to measurable 5-methyltetrahydrofolate in cerebrospinal fluid in methylenetetrahydrofolate reductase deficiency. JIMD Rep. 2016;29:103-7.

32. Scaglione F, Panzavolta G. Folate, folic acid and 5-methyltetrahydrofolate are not the same thing. Xenobiotica. 2014:44(5):480-8.

33. Wang L, Jiang H, Grinvald A, Jayadev C, Wang J. A mini review of clinical and research applications of the retinal function imager. Curr Eye Res. 2018; 43(3):273-88.

34. Chen D, Wang J, Dan Z, Shen X, Ci D. The relationship between methylenetetrahydrofolate reductase C677T polymorphism and diabetic retinopathy: a meta-analysis in multiethnic groups. Ophthalmic Genet. 2018; 39(2):200-7

35. Malaguarnera G, Gagliano C, Salomone S, Giordano M, Bucolo C, Pappalardo A, et al. Folate status in type 2 diabetic patients with and without retinopathy. Clin Ophthalmol. 2015;9:1437-42.

36. Coral K, Angayarkanni N, Gomathy N, Bharathselvi M, Pukhraj R, Rupak R. Homocysteine levels in the vitreous of proliferative diabetic retinopathy and rhegmatogenous retinal detachment: its modulating role on lysyl oxidase. Invest Ophthalmol Vis Sci. 2009;50(8):3607-12.

37. Hassan A, Hunt BJ, O'Sullivan M, Bell R, D'Souza R, Jeffery S, et al. Homocysteine is a risk factor for cerebral small vessel disease, acting via endothelial dysfunction. Brain. 2004:127(Pt 1):212-9.

38. Cabrera DeBuc D, Somfai GM, Arthur E, Kostic M, Oropesa S, Mendoza Santiesteban C. Investigating multimodal diagnostic eye biomarkers of cognitive impairment by measuring vascular and neurogenic changes in the retina. Front Physiol. 2018;9:1721.

39. Dumitrascu OM, Demaerschalk BM, Valencia Sanchez C, Almader-Douglas D, O'Carroll CB, Aguilar MI, et al. Retinal microvascular abnormalities as surrogate markers of cerebrovascular ischemic disease: a meta-analysis. J Stroke Cerebrovasc Dis. 2018;27(7):1960-8.

40. Nunes S, Pires I, Rosa A, Duarte L, Bernardes R, Cunha-Vaz J. Microaneurysm turnover is a biomarker for diabetic retinopathy progression to clinically significant macular edema: findings for type 2 diabetics with nonproliferative retinopathy. Ophthalmologica. 2009;223(5):292-7.

41. Wilcken B, Bamforth F, Li Z, Zhu H, Ritvanen A, Renlund M, et al. Geographical and ethnic variation of the $677 \mathrm{C}>\mathrm{T}$ allele of 5,10 methylenetetrahydrofolate reductase (MTHFR): findings from over 7000 newborns from 16 areas world wide. J Med Genet. 2003;40(8):619-25. 
42. Heifetz EM, Birk RZ. MTHFR C677T polymorphism affects normotensive diastolic blood pressure independently of blood lipids. Am J Hypertens. 2015;8(3):387-92

43. Schmidl D, Werkmeister R, Szegedi S, Bata A, Stjepanek K, Puchner S, Garhofer $\mathrm{G}$. The effect of folate supplementation on systemic homecysteine plasma concentration and ocular blood flow in patients with diabetes. In: Schweizerische Opthalmologische Gesellschaft (SOG) Annual conference. Friborg; 2018.

44. Gopinath B, Wang JJ, Flood VM, Burlutsky G, Wong TY, Mitchell P. The associations between blood levels of homocysteine, folate, vitamin B12, and retinal vascular caliber. Am J Ophthalmol. 2009;148(6):902-9.

45. Mrad M, Wathek C, Saleh MB, Baatour M, Rannen R, Lamine K, et al. Association of methylenetetrahydrofolate reductase (A1298C and C677T) polymorphisms with retinal vein occlusion in Tunisian patients. Transfus Apher Sci. 2014;50(2):283-7.

46. Heath AK, Williamson EJ, Hodge AM, Ebeling PR, Eyles DW, Kvaskoff D, et al. Vitamin D status and the risk of type 2 diabetes: The Melbourne Collaborative Cohort Study. Diabetes Res Clin Pract. 2018;2019(149):179-87.

47. Rafiq $S$, Jeppesen PB. Is hypovitaminosis D related to incidence of type 2 diabetes and high fasting glucose level in healthy subjects: A systematic review and meta-analysis of observational studies. Nutrients. 2018;10(1):59.

48. Lucato P, Solmi M, Maggi S, Bertocco A, Bano G, Trevisan C, et al. Low vitamin $D$ levels increase the risk of type 2 diabetes in older adults: $A$ systematic review and meta-analysis. Maturitas. 2017;100:8-15.

49. Bonakdaran S, Shoeibi N. Is there any correlation between vitamin D insufficiency and diabetic retinopathy? Int J Ophthalmol. 2015;8(2):326-31.

50. Alcubierre N, Valls J, Rubinat E, Cao G, Esquerda A, Traveset A, et al. Vitamin $D$ deficiency is associated with the presence and severity of diabetic retinopathy in type 2 diabetes mellitus. J Diabetes Res. 2015;2015:374178.

Ready to submit your research? Choose BMC and benefit from:

- fast, convenient online submission

- thorough peer review by experienced researchers in your field

- rapid publication on acceptance

- support for research data, including large and complex data types

- gold Open Access which fosters wider collaboration and increased citations

- maximum visibility for your research: over $100 \mathrm{M}$ website views per year

At $\mathrm{BMC}$, research is always in progress.

Learn more biomedcentral.com/submissions 